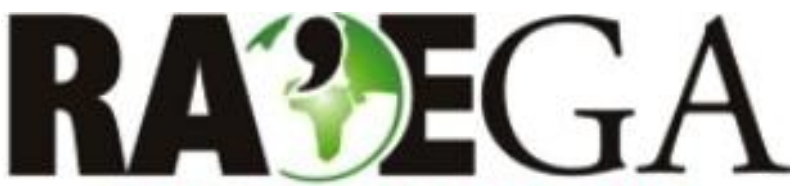

O ESPAÇO GEOGRÁFICO EM ANÁLISE

\title{
MAPEAMENTO DE ANTROPOSSOLOS: ESTUDO DE CASO NO BAIRRO SANTA FELICIDADE (CURITIBA/PARANÁ)
}

\author{
MAPPING OF ANTHROSOLS: CASE STUDY IN DISTRICT SANTA FELICIDADE \\ (CURITIBA/PARANÁ)
}

\author{
Mariana Andreotti Dias ${ }^{1}$, Eduardo Vedor de Paula ${ }^{2}$
}

\section{RESUMO}

A urbanização e as modificações no uso da terra que lhe são associadas geram alterações na paisagem natural na qual o solo, como um de seus elementos formadores, é submetido a degradações cada vez mais expressivas. Os resultados dessas intervenções antropogênicas foram organizadas em forma de taxonomia no documento "ANTROPOSSOLOS - proposta de ordem (1a aproximação)" da Embrapa em 2004, onde propõem-se tipologias que indicam três principais ações humanas: a adição de materiais, a decapitação (retirada parcial ou total do solo) e a mobilização (movimentação parcial ou total dos solos). A aplicação e validação dessas tipologias são os objetivos centrais desse trabalho, realizado na porção norte do bairro de Santa Felicidade (noroeste da cidade de Curitiba, Estado do Paraná), caracterizada pela diversidade de ambientes naturais associada ao recente e intenso processo de alteração do uso e ocupação do solo, e o consequente adensamento urbano. Todos os procedimentos metodológicos são expostos para justificar a obtenção dos objetivos específicos como: a construção do mapa de cobertura vegetal e uso da terra atualizado para o ano de 2014; o ajuste dos solos remanescentes encontrados à escala de análise e a construção do mapa de Antropossolos na escala de 1:20.000. Esse mapeamento permitiu confirmar a existência de cinco grandes grupos na região, considerados até o $3^{\circ}$ nível taxonômico. A análise integrada de elementos físicos permeou todo o desenvolvimento do trabalho, que se entende como um método satisfatório e válido para novos estudos.

Palavras-chave: solos antropogênicos; uso do solo; Santa Felicidade.

\section{ABSTRACT}

The urbanization and the land use modifications associated with that, generate changes in the natural landscape in which, the soil as one of its elements is submitted to an increasing process of degradation. The results of these anthropogenic interventions were organized as a taxonomy in the document "Anthropossolos - proposal for order (1st approximation)" by Embrapa in 2004. The organization is given by typologies that indicate three main actions practiced by man: the addition of materials, decapitation (partial or total removal of the soil) and mobilization (partial or total movement of the soil). The application and validation of these types are the central objectives of this work. The neighborhood of Santa Felicidade (northwest portion of Curitiba / Paraná) was chosen as a study area, due to the diversity of natural environments, associated with the recent and intense process of alteration of land use and occupation and consequent urban densification. All methodological procedures are exposed to justify the award of the specific objectives as: the construction of vegetation maps and use of updated land for the year 2014; the adjustment of natural soils found on the scale of analysis and the construction of Anthrosols map on the scale of 1: 20.000. This mapping allowed to confirm the existence of five major groups in the region, considered to the 3rd level categorical. The integrated analysis of physical elements of the landscape permeated all development work which is confirmed by a satisfactory method valid for new studies.

Key-words: anthropization of Soil; use of land; Santa Felicidade.

Recebido em: 25/11/2016

Aceito em: 18/12/2017

\footnotetext{
${ }^{1}$ Universidade Federal do Paraná, Curitiba/PR, email: mariana_andreotti_d@hotmail.com

${ }^{2}$ Universidade Federal do Paraná, Curitiba/PR, email: edugeo@ufpr.br
} 


\section{MAPEAMENTO DE ANTROPOSSOLOS: ESTUDO DE CASO NO BAIRRO SANTA FELICIDADE (CURITIBA/PARANÁ)}

\section{INTRODUÇÃO}

A segunda metade do século XX é reconhecida como o período das grandes mudanças econômicas no Brasil, cenário esse advindo da industrialização e expansão das cidades. Segundo dados do IBGE (2000), o Brasil transformou-se de um país rural a urbano em 60 anos: $31,3 \%$ da população vivia em centros urbanos em 1940 e $81,2 \%$ em 2000. Já no último censo, de 2010, os registros apontam que, da população total do país, $84 \%$ é urbana e $16 \%$ rural. A urbanização se deu de maneira acelerada e destituída de planos orientadores para o crescimento ordenado dos tecidos urbanos.

Conforme já observava Ab'Saber (1969, p.2), "evidentemente, variações sutis de fisiologia podem ser determinadas por ações antrópicas predatórias, as quais na maior parte dos casos são irreversíveis em relação ao 'metabolismo' primário do meio natural". De acordo com Ojima e Hogan (2008 p. 8), "centros urbanos monocêntricos densos apresentam aspectos ambientalmente desfavoráveis em escala local". Dentre esses aspectos cita-se a impermeabilidade pela ocupação adensada, que modifica a dinâmica hidrológica e aumenta o risco de enchentes, erosões, alargamento de canais, incidência de zoonoses, desrespeito às condições topo-pedológicas locais, elevação do albedo em áreas construídas, uso dos terrenos e das águas para descarte de resíduos não tratados e insuficiência de vegetação no ambiente urbano. Esses são alguns dos problemas que afetam direta e indiretamente a qualidade de vida nas cidades.

Os solos em meio urbano, como parte desse processo, são citados por Schleub et al. (1998, p.19): "no processo de urbanização planejado, a aptidão de uso dos solos deve ser considerada, observando suas potencialidades e respeitando suas limitações e fragilidades". Os autores indicam a importância de se levar em conta os estudos da pedologia no planejamento urbano, porém estes não são restritos apenas às cidades, conforme indica Silva (2011, p.48): “a utilização de grandes áreas para prática da agricultura, pecuária e moradia promovem profundas alterações nas características dos solos".

O termo "solo" pode ser apresentado por conceituações diversas, dentro da Pedologia, ciência responsável pelo seu estudo, trata-se de uma camada de formação superficial organizada e estruturada, remetendo a uma origem e classificação. Para Giasson (2010, p.1), “(...) a maioria dos geólogos e engenheiros civis é visualizado como sinônimo de regolito ou rocha alterada.". Quando usado dentro do viés do planejamento e gestão urbana, o termo "solo" opera na lógica da organização territorial necessária tendo em vista o adensamento, que é “(...) a intensificação do uso e ocupação do solo vinculando a disponibilidade de infraestrutura e as condições do meio ambiente.". (SECCHI et al., 2005, p.12). Nota-se a diferenciação no seu uso, ora como material enterrado, ora como suporte para estruturas.

Esses volumes presentes nas cidades apresentam deficiências em comparação aos solos remanescentes, ou solos naturais livres da intervenção humana como a baixa capacidade de resiliência, devendo-se ressaltar que sua função ecológica pouco é explicitada, embora seja de suma importância. Poyat et al. (2010, p.119) afirmam que "os solos urbanos oferecem uma gama de serviços ecológicos para os habitantes de uma cidade, tais como servir de aporte para plantas e estruturas construídas, regular o ciclo hidrológico, purificação das águas, armazenamento de carbono e nutrientes minerais".

Lepsch (1993, p.83) exemplifica a eficiência morfológica dos latossolos no meio urbano, atuando como excelentes fontes de matéria prima para aterros, estradas e barragens de terras, além de permitir a construção de fossas sépticas pela elevada permeabilidade. Entretanto, o processo de compactação desses solos reduz a compressibilidade e permeabilidade ocasionada pela redução da porosidade do solo.

As modificações mais frequentes impostas ao solo pelo inchaço das cidades (obras 


\section{MAPEAMENTO DE ANTROPOSSOLOS: ESTUDO DE CASO NO BAIRRO SANTA FELICIDADE (CURITIBA/PARANÁ)}

civis, manejo do solo) demandam iniciativas que amenizem o atual cenário de degradação.

\begin{abstract}
"Do ponto de vista da gênese dos solos, a destruição e formação de solos pelo homem, pela grande manipulação física dos materiais terrosos, são eventos catastróficos que criam novos pontos de partida para a formação dos solos". (FANNING e FANNING, 1989 apud PELOGGIA, 1997, p.258).
\end{abstract}

No presente estudo, o objetivo é classificar, por meio da proposta de "Ordem dos Antropossolos" (CURCIO et al., 2004), os solos antropizados em áreas urbanas, esses encontrados na porção norte do bairro de Santa Felicidade (Curitiba, Paraná). Além da classificação e dos produtos cartográficos, pretende-se verificar se a taxonomia apresentada no documento de fato supre as especificidades que esses solos alterados possuem. Almejando assim, confirmar a existência e o grau de degradação dos mesmos.

\subsection{A IMPORTÂNCIA DE SE CLASSIFICAR SOLOS URBANOS}

Pedron et al. (2007, p.147) expõe que "o mapeamento e classificação dos solos, ao considerar suas características e propriedades morfológicas, físicas, químicas e mineralógicas, permitem determinar o potencial de uso da terra.". A ausência dessas informações prejudica a classificação que é extremamente necessária para a organização dos volumes pedológicos.

Uma alternativa para o reconhecimento de solos degradados em meio urbano é o enquadramento taxonômico das classes e uma metodologia que apresente sistematicamente processo de mapeamento. A classificação dos solos é uma prática antiga e fundamental: "seu levantamento e mapeamento devem ser considerados básicos para o planejamento de ações dirigidas à conservação natural e à qualidade desses ambientes" (PEDRON et al., 2007, p.2). Tal classificação implica em uma estrutura que organize e especifique as características fundamentais dos solos, além de ser um meio de comunicação entre os cientistas e aqueles que utilizam o território.

Os solos urbanos não possuem uma classificação completa, sendo tarefa árdua encontrá-la em documentos, sendo perceptível o abismo existente entre os percalços decorrentes da urbanização e o conhecimento científico ainda incipiente nessa questão. Portanto, é pertinente e necessidade a inclusão dos solos urbanos nos sistemas de classificações taxonômicos.

\footnotetext{
“Uma vez que estes sistemas são a base para os sistemas interpretativos e para a elaboração dos mapas de solos, tal inclusão representa um salto na capacidade de definir a vocação (urbana) do uso dos solos, contribuindo no planejamento das cidades." (PEDRON et al., 2004, p.2)
}

Diversos países adequaram suas classificações tradicionais, que contemplam solos naturais, a esses volumes antropizados, sendo que muitos se espelharam na Food and Agriculture Organization (FAO) e na sua taxonomia World Reference Base for Soils Resources (IUSS Working Group WRB, 2014), são eles: Austrália ${ }^{3}$, EUA $^{4}$ Polônia $^{5}$, Canadá $^{6}$, Áustria $^{7}$ e França ${ }^{8}$.

Outros como: Rússia ${ }^{9}$, Inglaterra e País de Gales $^{10}$, Alemanha ${ }^{11}$, Japão ${ }^{12}$ e China $^{13}$ construíram suas classificações levando em conta as especificidades de suas regiões. Entretanto,

\footnotetext{
${ }^{3}$ The Australian Soil Classification, publicado em 2016.

4 Soil Taxonomy, publicado em 2014.

${ }^{5}$ Technogenic Soils of Poland, publicado em 2013.

${ }^{6}$ Canadian System of Soil Classification, publicado em 2011

7 Systematische Gliederung der Böden Österreichs, publicado em 2011.

${ }^{8}$ Référentiel Pédologique, publicado em 2008.

9 Russian Soil Classification, publicado em 2000.

10 The Soil Classification United Kingdom of Great Britain Northern Ireland, publicado em 1980.

11 Deutsche Bodenkundlice Gesellschaft, publicado em 2010.

12 Soil Classification System of Japan, publicado em 2015.

${ }^{13}$ Chinese Soil Taxonomy, publicado em 2011.
} 


\section{MAPEAMENTO DE ANTROPOSSOLOS: ESTUDO DE CASO NO BAIRRO SANTA FELICIDADE (CURITIBA/PARANÁ)}

pesquisadores dessas nacionalidades auxiliaram a FAO no documento WRB, de 2014.

No Brasil, os pesquisadores Curcio, Lima e Giarola, da Embrapa Florestas (Empresa Brasileira de Pesquisas Agropecuárias), em 2004 lançaram a primeira aproximação da "Ordem dos Antropossolos". A discussão foi pautada em adequar os volumes pedológicos a uma classificação que auxilie os estudiosos de solos em suas pesquisas, facilitando o diálogo entre os interessados e sustentando a ideia de que somente a partir de um reconhecimento é possível planejar alternativas para reverter 0 cenário degradante dos ambientes modificados.

\subsection{NOMENCLATURAS ALTERNATIVAS PARA OS SOLOS MODIFICADOS PELA AÇÃO HUMANA}

Ressalta-se que há, além da abordagem adotada neste trabalho, diferentes propostas que tratam da análise, descrição e classificação dos materiais aqui estudados, em que além de "solos urbanos" são usados conceitos como "solos antrópicos", "depósitos e solos tecnogênicos", "terrenos artificiais", "antropossolos" e "tecnossolos".

Os "solos urbanos", segundo autores como Craul (1992), Stroganova et al., (1993), De Kimpe e Morel (2000), Schueler (2000), Pedron (2004) e Pouyat et al. (2010), são entendidos como volumes que se encontram em meio urbano e cujas propriedades químicas, físicas e biológicas são constantemente alteradas. A distinção das características pedológicas fica comprometida e comumente são encontrados outros componentes em suas estruturas como os metais pesados, materiais orgânicos e inorgânicos de origem humana. Todas essas especificações são o reflexo do uso e ocupação da cobertura pedológica pela humanidade.

Já o conceito de "solos antrópicos" refere-se à exploração agrícola, mineral e urbana. Diferenciam-se, assim, dos solos urbanos por estarem espacialmente distribuídos tanto em áreas urbanas como em áreas rurais. Muitos sistemas de classificação de solos mundiais utilizam o termo solos antrópicos, simplificando a nomenclatura e expandindo a ocorrência desses volumes (PEDRON et al., 2004).

A proposta dos conceitos de solos e depósitos tecnogênicos, por outro lado, refere-se a registros geológicos correlativos da agência humana. (PELOGGIA, 1997, 1998, 2005).

Peloggia (1997, 1998) e Machado (2013) apontam que os depósitos tecnogênicos são formações superficiais resultantes de processos de agradação (como aterros e morrotes artificiais e planícies aterradas) com influência direta ou indireta da ação do homem, que resulta negativamente nos processos ambientais. Esses processos ambientais são exemplificados por Peloggia (1997, p. 258):

\footnotetext{
- $\quad$ Alterações fisiográficas da paisagem: retificação de canais fluviais, terraplanagens, voçorocas, áreas erodidas, áreas mineradas, aterros sanitários;

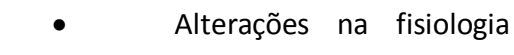
das paisagens: drenagem pluvial e fluvial, taxas de sedimentação, fluxos subterrâneos, efeitos tectônicos, incremento de erosão e da carga sedimentar e demais processos que necessitam de outra organização da fisiologia da paisagem decorrente do construtivismo;

- Criação de depósitos superficiais correlativos: (processos exógenos) desmonte de rochas em minas de construção, escavações e transferências de solos, aterramentos, retificação de rios, escavações e sobrecarregamentos de taludes e encostas; (processos semi-endógeno) sismos induzidos por obras de engenharia, escavações mineiras ou injeções de água e resíduos líquidos em camadas profundas.
}

Conforme o autor citado, as alterações supracitadas são mais evidentes em áreas urbanas onde a ação modificadora do homem sobre a natureza, geológica se amplia e diversifica prejudicando o bem estar social e ambiental (PELOGGIA, 1997). 


\section{MAPEAMENTO DE ANTROPOSSOLOS: ESTUDO DE CASO NO BAIRRO SANTA FELICIDADE (CURITIBA/PARANÁ)}

Por outro lado, “ANTROPOSSOLO ${ }^{14 ”}$ é a nomenclatura utilizada por Curcio et al., (2004) para os "solos que apresentam drástica intervenção humana, por meio de processos como a incorporação de materiais inertes e/ou a retirada parcial do solo, com no mínimo $40 \mathrm{~cm}$ de profundidade." (CURCIO et al., 2004, p. 21). As principais características dessa ordem de solo se dão pela morfologia variável, devido à proveniência antrópica dos materiais constitutivos; a composição e tempo de formação distintos e o pequeno grau de evolução, tendo em vista a baixa relação pedogenética entre as camadas existentes neste tipo de solo. (CURCIO et al., 2004).

Como no Brasil a discussão sobre os solos alterados ainda é incipiente optou-se por adequar a presente pesquisa a proposta de Curcio et al., (2004). Algo que não infere nenhuma percalço a classificação.

\subsection{ORDEM DOS ANTROPOSSOLOS}

A Ordem dos ANTROPOSSOLOS faz parte de uma abordagem que não está inserida no Sistema Brasileiro de Classificação de Solos (SiBCS) da EMBRAPA, mas possui um potencial elevadíssimo para a ciência dos solos e o planejamento ambiental.

Como esses solos foram alterados, eles guardam características muito distantes do seu natural, dessa forma existem peculiaridades, sendo necessária a minuciosidade no seu tratamento. São os volumes em maior expansão no Brasil e no mundo devido à modernização e modificação dos espaços. Apesar de ser óbvia a alteração nos centros urbanos, as áreas rurais também são alvo de mudanças do solo pela deposição de lixos, remoção de horizontes superficiais, mineração, práticas operacionais em áreas de salinas, entre outras.

O conceito adequado para a classificação foi posto em voga, preferencialmente usa-se camada antrópica invés de horizonte antrópico,

\footnotetext{
14 Observe-se que este termo não é utilizado "oficialmente" no Brasil em razão da não regulamentação do mesmo pelo SiBCS. (Sistema Brasileiro de Classificação de Solos).
}

isso se deve em razão do tempo que um solo leva para se estruturar devido à natureza impeditiva dos materiais constituintes. Camadas com espessuras inferiores ou iguais a 40 centímetros são enquadradas como camadas antrópicas. Os materiais antrópicos são de natureza mineral ou orgânica produzidos pelo homem.

A necessidade da criação da ordem dos ANTROPOSSOLOS é presente. Como pelo exemplo dado por Curcio et al., (2004, p.13) que:

"Investigando solos de área urbana de Curitiba, constatou a inversão e mistura de horizontes, perfis decapitados, abruptas variações na granulometria, densidades elevadas e eutrofização de horizontes originalmente álicos, além da presença de materiais de natureza antrópica variada". (EMBRAPA, 2004).

A avaliação de um solo demanda alguns cuidados essenciais para se chegar a sua classificação. Curcio et al. (2004) alertam que volumes pedogenéticos podem estar associados a lugares aparentemente naturais que sua formação antigamente foi de caráter antrópico e com o passar do tempo foram gradualmente recobertos por vegetação natural, deixando margem ao erro.

\footnotetext{
"A necessidade de que técnicos e pesquisadores de solos, incluindo também aqueles que trabalham com questões relacionadas ao meio ambiente, tenham em mãos, dentro do SiBCS, uma forma organizada de entendimento sobre esses volumes criados pelo homem, para poder se reportar com maior especificidade às suas potencialidades e fragilidades ambientais". (CURCIO et al. , 2004, p.11).
}

Não sendo encontrada tal descrição na atual classificação brasileira de solos justifica-se a necessidade de estruturação taxonômica dos solos modificados por ações antrópicas.

As três grandes ações desempenhadas pelo homem consideradas na proposta são: 


\section{MAPEAMENTO DE ANTROPOSSOLOS: ESTUDO DE CASO NO BAIRRO SANTA FELICIDADE (CURITIBA/PARANÁ)}

adição (considerando a incorporação/mistura de materiais); decapitação (retirada parcial ou total) e mobilização (movimentação parcial ou total de solos).

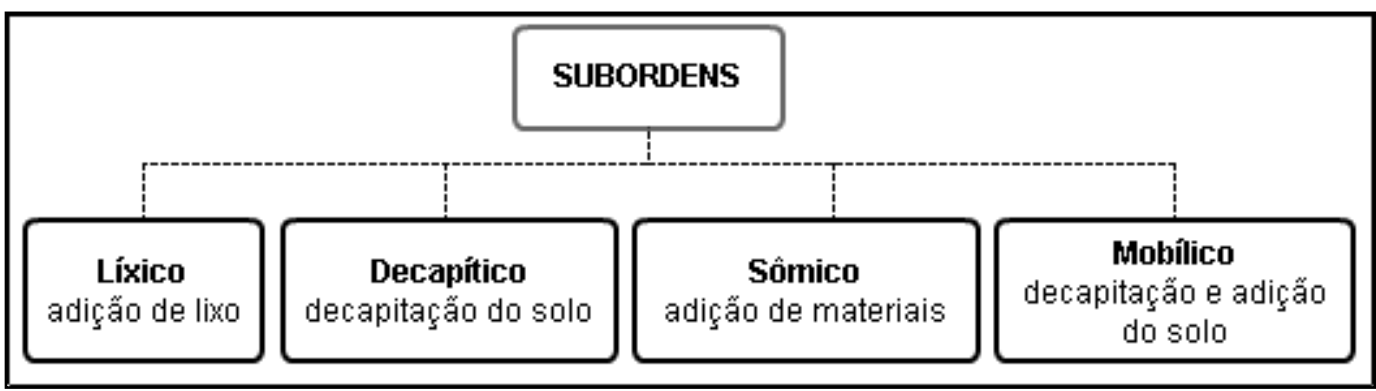

Figura 1- Chave de classificação dos Antropossolos.

A proposta de Curcio et al. (2004) é dividida em quatro níveis categóricos: $1^{\circ}$ nível Ordem dos ANTROPOSSOLOS; $2^{\circ}$ nível Subordens (LíXICO, DECAPÍTICO, SÔMICO e MOBílICO); $3^{\circ}$ nível - Grandes Grupos (dezesseis ao total); $4^{\circ}$ nível - Subgrupos (noventa categorias classificatórias, onde a classificação nesse nível demanda exclusivamente de análise química).(Quadro

1).

Quadro 1 - Elementos formativos e significados das subordens, grandes grupos e subgrupos da Ordem dos ANTROPOSSOLOS.

\begin{tabular}{|c|c|c|}
\hline CLASSE & $\begin{array}{c}\text { ELEMENTO } \\
\text { FORMATIVO }\end{array}$ & TERMOS DE CONOTAÇÃO E MEMORIZAÇÃO \\
\hline \multicolumn{3}{|r|}{ SUBORDENS } \\
\hline LÍXICO & Líx & Lixo. Detritos domésticos ou industriais. \\
\hline DECAPÍTICO & Decapít & Decapitado. Remoção de horizonte do solo. \\
\hline SÔMICO & Som & Soma. Adição de horizontes do solo. \\
\hline MOBÍLICO & Mobil & Mobilização. Movimentação de horizontes do solo. \\
\hline \multicolumn{3}{|r|}{ GRANDES GRUPOS } \\
\hline Áquico & Áqu & Água. Sujeito à saturação por água. \\
\hline Órtico & Órt & Típico. Condição habitualmente encontrada. \\
\hline Totálico & Total & Inteiro. Retirada total do solo. \\
\hline Parciálico & Parcial & Parte. Retirada parcial do solo. \\
\hline Mésclico & Méscl & Mistura. Mistura de horizontes de solo. \\
\hline Camádico & Camad & Camada. Materiais dos solos dispostos em camada. \\
\hline Équico & Équ & Igual. Camadas dos solos dispostos semelhantes ao original. \\
\hline Inéquico & Inéqu & Desigual. Camadas dispostas não semelhantes ao solo original. \\
\hline \multicolumn{3}{|r|}{ SUBGRUPOS } \\
\hline Tóxico & Tóx & Nocivo. Presença de materiais nocivos ao ambiente. \\
\hline Séptico & Sépt & Nocivo. Presença de organismos patogênicos. \\
\hline Eutrófico & Eutróf & Rico. Alta saturação por base. \\
\hline Distrófico & Distróf & Pobre. Baixa saturação por base. \\
\hline Alumínico & Alumín & Alumínio. Altos teores de alumínio trocáveis. \\
\hline
\end{tabular}


DIAS, M. A., PAULA, E. V.

MAPEAMENTO DE ANTROPOSSOLOS: ESTUDO DE CASO NO BAIRRO SANTA FELICIDADE (CURITIBA/PARANÁ)

\begin{tabular}{|c|c|c|}
\hline Homogênico & Homogên & Homogêneo. Constituição uniforme. \\
\hline Heterogênico & Heterogên & Heterogêneo. Constituição desuniforme. \\
\hline Saprolítico & Saprolít & Decomposto. Rocha intemperizada. \\
\hline
\end{tabular}

Em razão do caráter diferenciado dos solos antrópicos para os solos remanescentes foi elaborada uma estruturação com precedência taxonômica, salientando que para a classificação nos níveis segundo e terceiro deve-se considerar o caráter morfológico e para o quarto nível há a necessidade de resultados analíticos laboratoriais para o enquadramento taxonômico.

A precedência taxonômica para o segundo nível hierárquico se dá do mais nocivo ao mais inócuo: LÍXICO > DECAPÍTICO > SÔMICO > MOBÍLICO.

\section{4. ÁREA DE ESTUDO}

A porção norte do bairro Santa Felicidade, localizado na região noroeste do município de Curitiba (Paraná), foi alvo da aplicação da ordem dos Antropossolos, no âmbito do presente estudo. Com uma área de $12,27 \mathrm{~km}^{2}$, o bairro apresenta uma diversidade de formas de relevo, vales, nascentes de rios, expressivas áreas ainda cobertas por vegetação em diferentes estágios de sucessão e diversos tipos de uso e ocupação do solo.

Uma carta de ANTROPOSSOLOS angariaria mais uma especificação à região, que tem sido alvo de estudos sobre o planejamento da paisagem e qualidade ambiental, dentre os quais: "Cobertura vegetal arbórea em condomínios residenciais horizontais do bairro
Santa Felicidade Curitiba/PR." (VALASKI et al., 2012); "Avaliação da qualidade ambiental urbana do bairro de Santa Felicidade, Curitiba/PR." (SCHMIDT, 2009); “Unidades de paisagem no bairro de Santa Felicidade (Curitiba/PR), como subsídio ao ordenamento da paisagem" (BELEM, 2013).

A escolha se justifica também pela diversificada paisagem da região que mantém fragmentos de vegetação nativa, chácaras familiares com pequenas produções agrícolas, edificações residenciais e comércio intenso. Sua localização e história de ocupação se configuram por resquícios de características rurais ao lado de características urbanas. Por esse cenário é possível obter amostras diversificadas que enriquecem o estudo.

O recorte da área de estudo (Figura 2) mostra o arruamento, as vias principais, a drenagem e a rugosidade do terreno. 0 perímetro proposto foi pensado em vista da viabilidade da aplicação da Ordem dos ANTROPOSSOLOS, fato esse que não exige uma extensão territorial grande. Dessa forma a porção norte da região, com $4,64 \mathrm{~km}^{2}$ ou $37,8 \%$ do total do bairro é uma área em expansão com espaços que podem ser ocupados ou remanejados (caso de chácaras que estão sendo substituídas por condomínios fechados). 


\section{MAPEAMENTO DE ANTROPOSSOLOS: ESTUDO DE CASO NO BAIRRO SANTA FELICIDADE} (CURITIBA/PARANÁ)

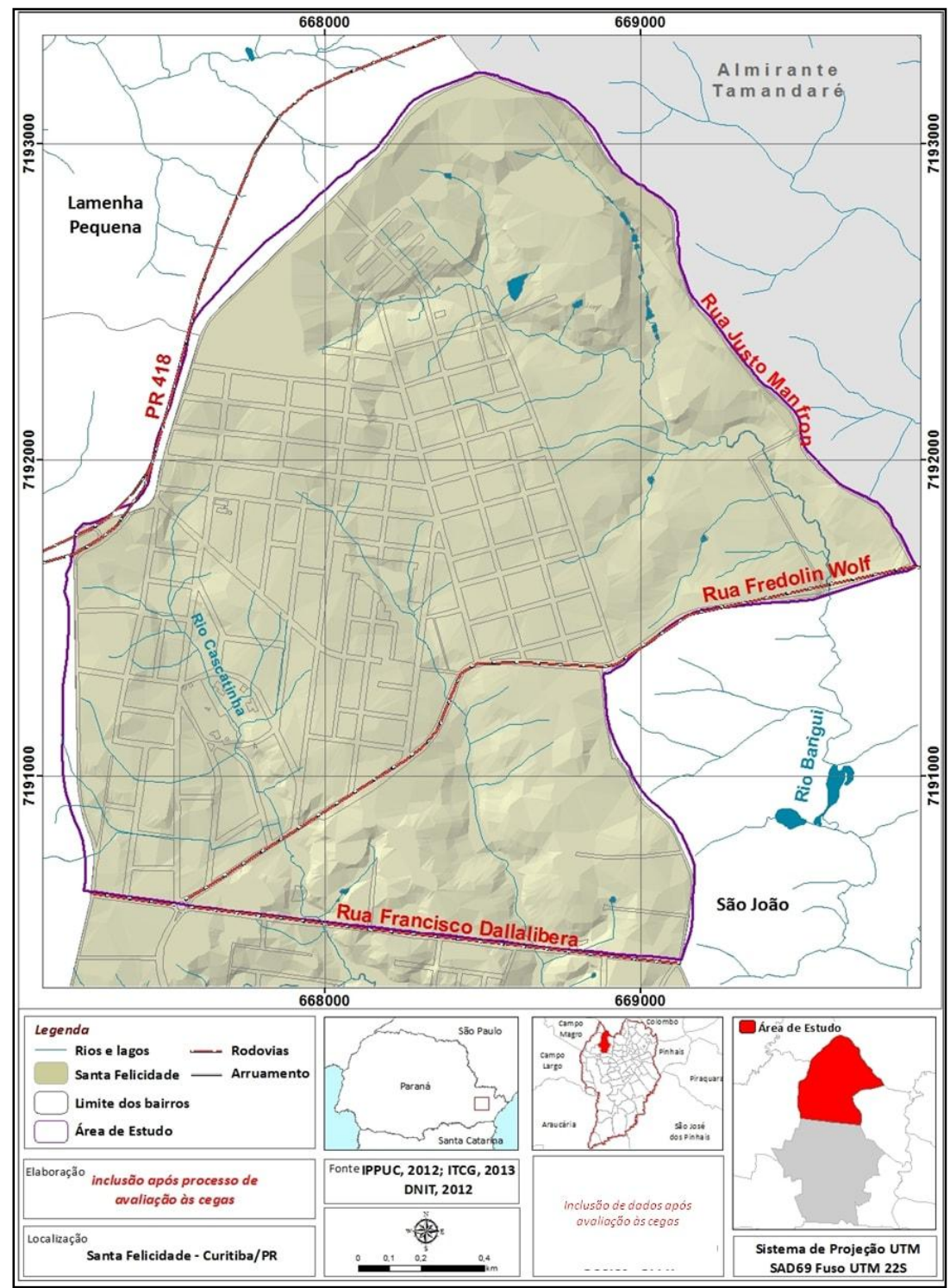

Figura 2 - Mapa de Localização da Área de Estudo.

\section{MATERIAIS E MÉTODOS}

Em relação aos métodos seguidos, a base norteadora do processo se fez através da consolidação do aporte teórico pautado no levantamento bibliográfico de pesquisas em Geopedologia (CURCIO et al., 2006) e
Planejamento da Paisagem (BERTRAND, 1972; DEUPOUX, 1974; MONTEIRO, 2000). Como também através do grupo de pesquisa do LABS Laboratório de Biogeografia e Solos da UFPR.

Os procedimentos metodológicos (Figura 3) seguiram a organização apresentada abaixo: 


\section{MAPEAMENTO DE ANTROPOSSOLOS: ESTUDO DE CASO NO BAIRRO SANTA FELICIDADE} (CURITIBA/PARANÁ)

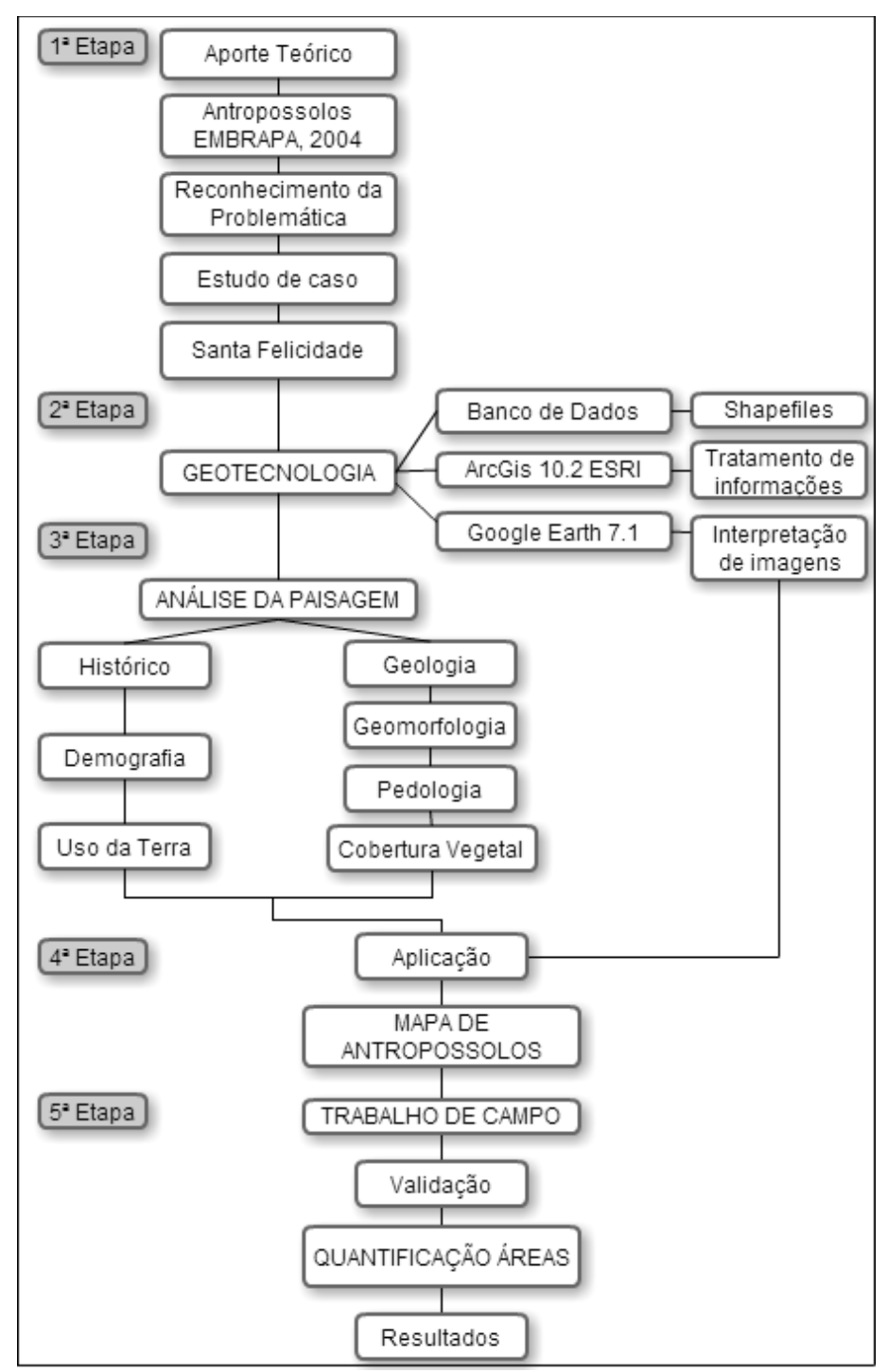

Figura 3 - Fluxograma metodológico.

$\mathrm{Na}$ primeira etapa o aporte teórico possibilitou o entendimento de como ocorreu a ocupação, urbanização e adensamento da área de estudo.

$\mathrm{Na}$ segunda etapa, o Sistema de Informações Geográficas (SIG) foi utilizado a fim de organizar cartograficamente os elementos da paisagem (geologia, geomorfologia, pedologia) da área de estudo. O mapeamento do uso da terra disponível para a região datava do ano 2000, algo que tornaria o estudo obsoleto caso fosse usado. Dessa forma, através das imagens aéreas de 2013 e 2014, disponíveis no Google Earth Pro ${ }^{\circledR}$, a atualização do mapa de uso da terra foi realizada, onde as feições vetoriais foram editadas e apresentadas em ambiente ArcGis 10.1 da $E S R I^{\circledR}$.

O cuidado ao representar essas feições foi tomado pela adequação da escala de mapeamento. O conceito da Área Mínima Mapeável presente no Manual Técnico de Pedologia (IBGE, 2007), define o tamanho da área que um determinado objeto deve possuir para que seja adequadamente representado em um mapa, sem a perda das informações levantadas em campo. Para o estudo, o cálculo corresponde a uma área de $0,4 \mathrm{~cm}^{2}(0,6 \mathrm{~cm} \times 0,6 \mathrm{~cm})$ com qualidade, ou seja, polígonos menores que esse valor devem ser generalizados. Dessa forma, a escala adequada de mapeamento é 1:20.000. 


\section{MAPEAMENTO DE ANTROPOSSOLOS: ESTUDO DE CASO NO BAIRRO SANTA FELICIDADE \\ (CURITIBA/PARANÁ)}

Na terceira etapa os aspectos históricos, sociais e ambientais levantados em laboratório fomentaram a construção do diagnóstico da área de estudo, colaborando com o esclarecimento de todas as ações praticadas pela população e representantes da região.

A cobertura vegetal fora identificada como natural de caráter conservado, fornecendo a ideia de que os solos que as sustentam são excluídos da antropização, assim os mesmos foram classificados como "solos remanescentes" e se enquadram no SiBCS.

$\mathrm{Na}$ quarta e quinta etapa chegou-se ao produto desse estudo. Através do trabalho de campo, com o percurso de todo perímetro a identificação dos locais com solos alterados foi possível. Imagens aéreas antigas da região permitiram que a história de ocupação fosse conhecida o que para o mapeamento dos ANTROPOSSOLOS é primordial.

Dessa forma, as classes foram identificadas, mapeadas e quantificadas a fim de mensurar quanto de antropização a região sofreu, designando especificamente qual o caráter dessas alterações e quais as tendências mais comuns para o caso.

\section{RESULTADOS E DISCUSSÕES}

A fim de verificar as mudanças ocorridas pela urbanização, foi gerado o mapeamento (Figura 4) e quantificação (Tabela 1) dos tipos de usos da terra (ano 2000 - desenvolvido pelo Instituto de Águas do Paraná) e atuais (2014) do bairro de Santa Felicidade, a partir da qual foi possível observar a ligação entre os sistemas socioeconômico e natural da região.

Tabela 1 - Quantificação das classes mapeadas.

\begin{tabular}{|c|c|c|c|c|c|}
\hline GRUPO & TIPOLOGIAS & $\begin{array}{l}\text { ÁREA } \\
2000\end{array}$ & $\begin{array}{r}\text { (ha }(\%) \\
2000\end{array}$ & $\begin{array}{l}\text { ÁREA (ha) } \\
\text { Ano } 2014\end{array}$ & $\begin{array}{l}(\%) \\
2014\end{array}$ \\
\hline \multirow{3}{*}{$\begin{array}{l}\text { AGRICULTURA/ } \\
\text { MINERAÇÃO }\end{array}$} & Exposto & 3,16 & 0,25 & 7,65 & 0,62 \\
\hline & Cultura Temporária & 23,49 & 1,91 & 21,25 & 1,73 \\
\hline & Mineração & - & - & 1,83 & 0,14 \\
\hline \multirow{2}{*}{ ÁREA EDIFICADA } & Urbana & 679,79 & 55,38 & 808,27 & 65,9 \\
\hline & Área Industrial & 1,18 & 0,09 & 1,18 & 0,09 \\
\hline \multirow{2}{*}{ CORPOS HÍDRICOS } & Cavas Abandonadas & 2,23 & 0,18 & 2,23 & 0,18 \\
\hline & Lagos Artificiais & 2,20 & 0,17 & 2,20 & 0,17 \\
\hline \multirow{4}{*}{ VEGETAÇÃO } & Vegetação & 308,16 & 25,1 & 300,75 & 24,5 \\
\hline & Campo/Pastagem & 203,18 & 16,5 & 79,33 & 6,49 \\
\hline & Reflorestamento & 3,98 & 0,32 & 2,71 & 0,22 \\
\hline & TOTAIS & 1227,4 & $100 \%$ & 1227,4 & $100 \%$ \\
\hline
\end{tabular}

Para aplicar as classes dos ANTROPOSSOLOS no bairro é imprescindível o conhecimento dos solos remanescentes, já que eles estão presentes na gênese da região, mesmo em volumes com alto grau de degradação antrópica. 
MAPEAMENTO DE ANTROPOSSOLOS: ESTUDO DE CASO NO BAIRRO SANTA FELICIDADE (CURITIBA/PARANÁ)

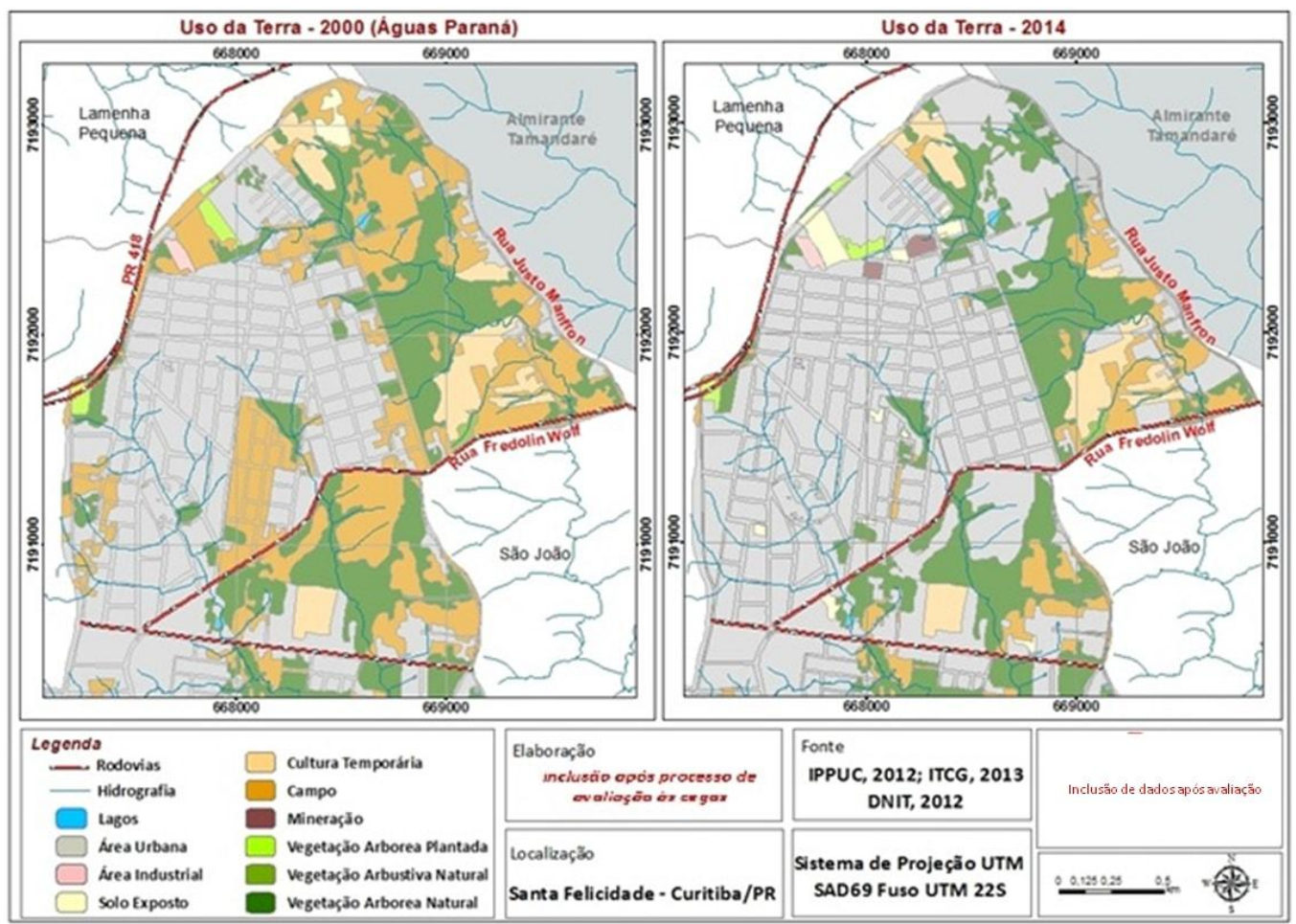

Figura 4 - Comparativo entre os Usos da Terra (2000 - 2014).

Na área de estudo o predomínio é dos Cambissolos Háplicos (CX) com extensão total de 401,05 ha. Na parte meridional da área de estudo foram encontrados os Latossolos Bruno (LB) com 63,53 ha.
Aplicando a classificação dos ANTROPOSSOLOS na área de estudo, foi encontrada uma percentual (Tabela 2) de 72,4\% de ANTROPOSSOLOS e $27,5 \%$ de Solos Remanescentes.

Tabela 2 - Quantificação das Classes.

\begin{tabular}{|c|c|c|c|}
\hline ORDEM & CLASSIFICAÇÃO PEDOLÓGICA & ÁREA (ha) & $(\%)$ \\
\hline \multirow{7}{*}{$\begin{array}{l}\text { ANTROPOSSOLOS } \\
72,4 \%\end{array}$} & ANTROPOSSOLOS DECAPÍTICO Parciálico & 46,1 & 9,9 \\
\hline & ANTROPOSSOLOS DECAPÍTICO Parciálico & & \\
\hline & Áquico & 1,1 & 0,2 \\
\hline & ANTROPOSSOLOS SÔMICO Mésclico & 3,3 & 0,7 \\
\hline & ANTROPOSSOLOS SÔMICO Mésclico & & \\
\hline & Áquico & 27,7 & 6,0 \\
\hline & ANTROPOSSOLOS MOBÍLICO Mésclico & 256,9 & 55,3 \\
\hline SOLOS & Cambissolo Hápli & & \\
\hline \multicolumn{4}{|l|}{ REMANESCENTES } \\
\hline $27,5 \%$ & Latossolo Bruno & 7,7 & 1,7 \\
\hline HIDROGRAFIA 0,2\% & Corpos Hídricos & 1,3 & 0,3 \\
\hline TOTAL & & 464,6 & $100 \%$ \\
\hline
\end{tabular}




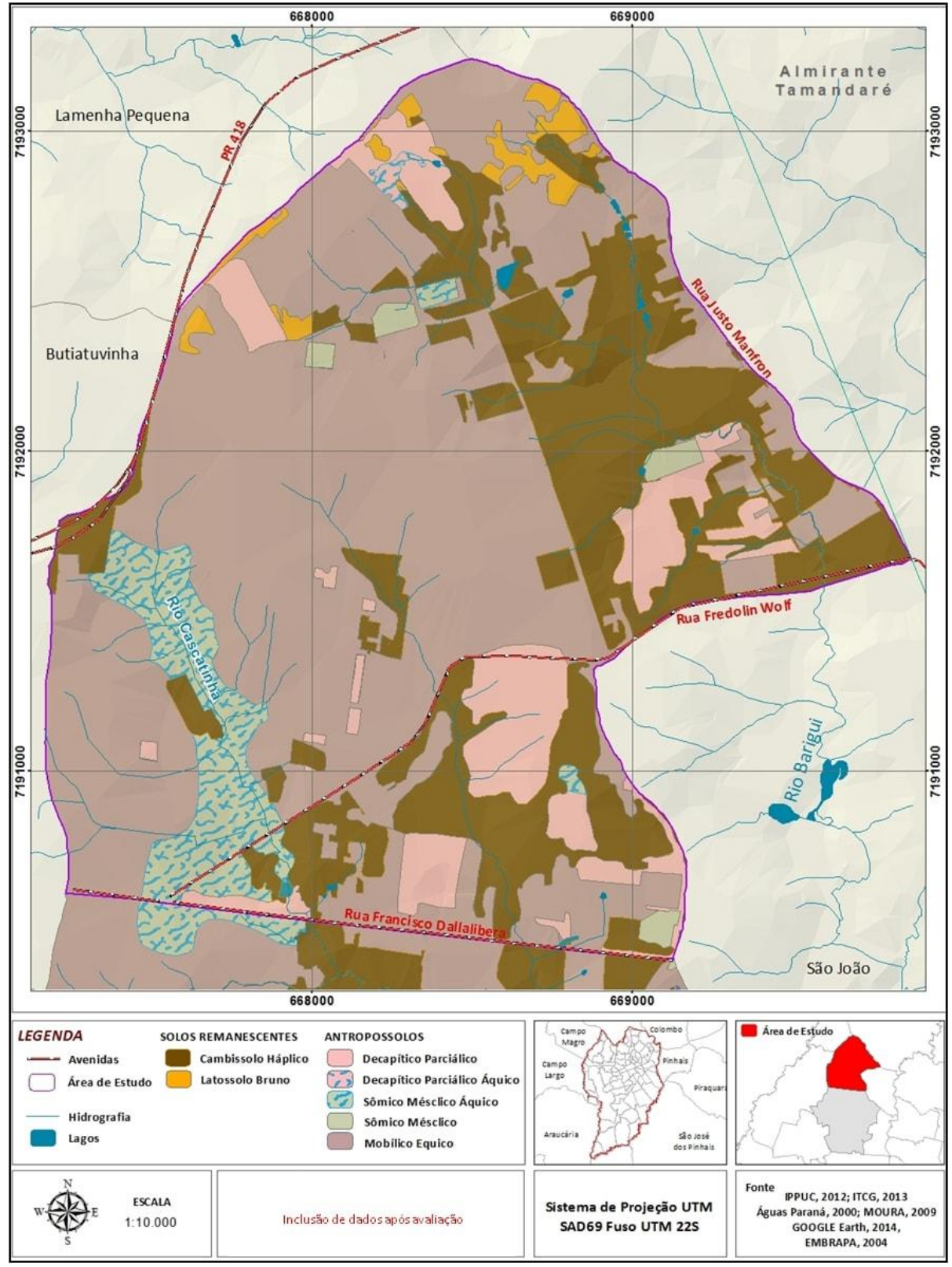

Figura 5 - Mapa de ANTROPOSSOLOS.

Foi possível verificar in loco a existência das cinco classes de ANTROPOSSOLOS (FIGURA 5). Embora não apareçam na escala de mapeamento, devido a área mínima mapeável ser de $0,4 \mathrm{~cm}^{2}$, foram encontrados na região ocorrências de ANTROPOSSOLOS LÍXICOS Órticos e ANTROPOSOLOS SÔMICOS Camádicos.

As classes encontradas em campo são ilustradas na Figura

6. 


\section{(CURITIBA/PARANÁ)}

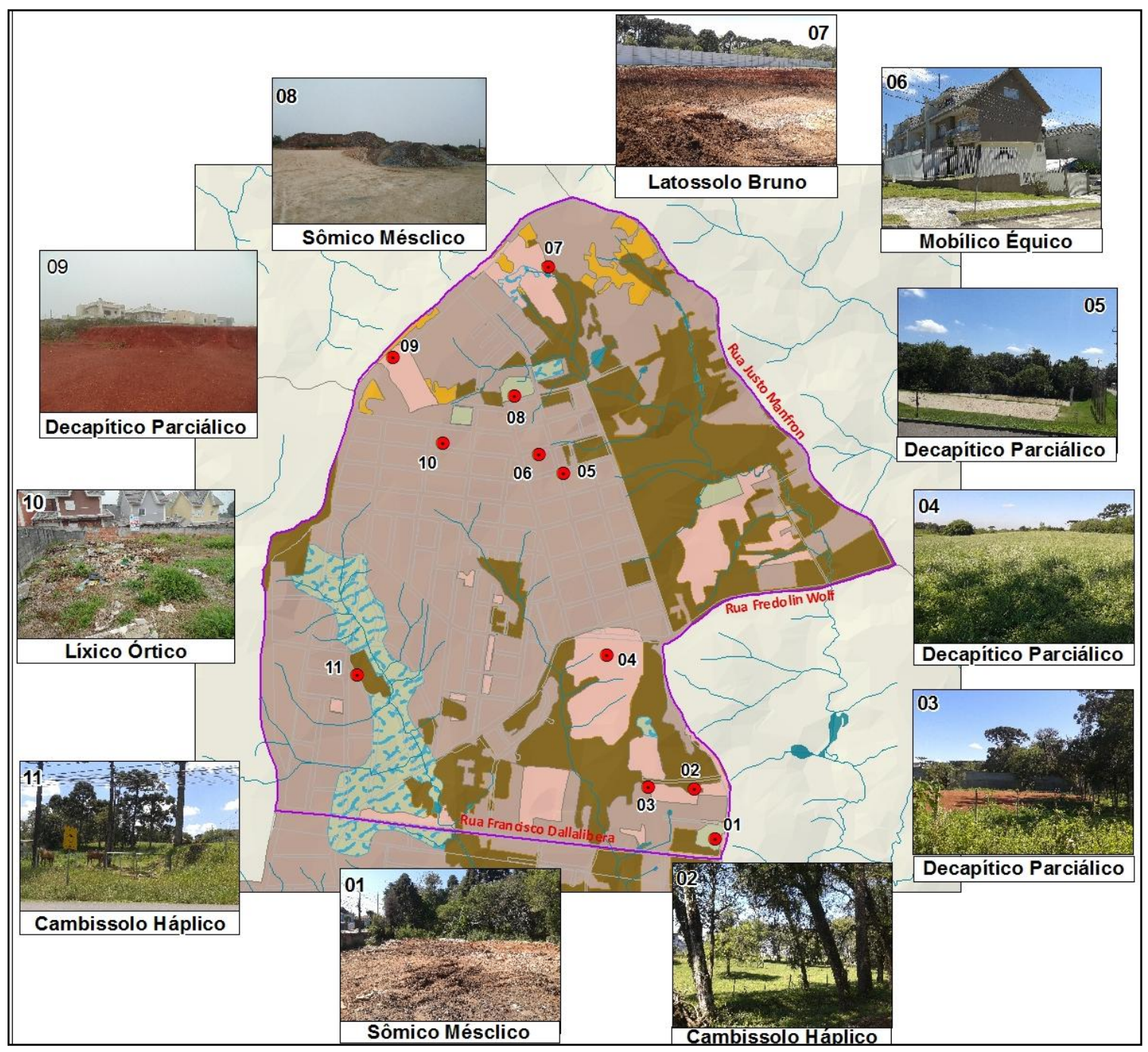

Figura 6 - Identificação dos Solos Alterados.

No ponto 01 (Figura 6) classificado como ANTROPOSSOLO SÔMICO Mésclico, nota-se a desorganização no terreno é uma área aberta com fragmentos de floresta natural. No ponto 02 o predomínio é do Cambissolo Háplico, verificouse a conservação do local, a existência de densa floresta e um declive suave do terreno. No ponto 03, devido a irregularidade no terreno, que em sua gênese apresenta declividade mais baixa, o volume indica a deposição de materiais (aterro), característico do ANTROPOSSOLO SÔMICO Camádico.

No ponto 04 é evidente a presença de vegetação em estágio inicial. No momento da aquisição da imagem, disponível no Google Earth, ano de 2013 , foi verificada a exposição do solo, o que auxiliou no entendimento da dinâmica histórica do local, confirmando que a área é utilizada para a agricultura, dessa forma considera-se o ANTROPOSSOLO DECAPÍTICO Parciálico. O ponto 05 , em razão do corte no terreno para a construção de quadras de futebol, a classe dos ANTROPOSSOLOS DECAPÍTICO Parciálicos evidenciam essa ação. No ponto 06 o ANTROPOSSOLO MOBÍLICO Équico é considerado dada a ocorrência da terraplanagem.

No ponto 07 foi possível comprovar a existência de um aterro, característico dos ANTROPOSSOLOS SÔMICOS Camádicos, sobre um Latossolo Bruno. No momento da visita ao local, foi possível presenciar a retirada parcial (não chega até o horizonte $\mathrm{C}$ ) do solo e a alteração do 


\section{MAPEAMENTO DE ANTROPOSSOLOS: ESTUDO DE CASO NO BAIRRO SANTA FELICIDADE (CURITIBA/PARANÁ)}

terreno. No ponto 08, foi encontrado um depósito de saibro e caliça da Prefeitura, esses materiais são recortados das vias da cidade e despejados no local, considerando-os como ANTROPOSSOLO SÔMICO Mésclico. O ponto 09 é um terreno que foi recortado para a construção de um condomínio fechado, por essa ação de retirada do solo a classe é caracterizada como ANTROPOSSOLO DECAPÍTICO Parciálico.

No ponto 10, uma condição habitualmente encontrada, com restos de lixos domésticos característicos da classe ANTROPOSSOLOS LíxicOS Órticos. A escolha e apresentação do termo "áreas de ocorrência" se fez com o intuito de não ignorar, em razão da escala, a presença dessa subordem bastante significativa para o meio ambiente. Por fim, o ponto 11 indica a existência de vegetação nativa que para o mapeamento dos ANTROPOSSOLOS foi intitulada como solos remanescentes, no caso cambissolo háplico, devido sua conservação e inexistência de ação antrópica degradante.

$\mathrm{Na}$ sequência serão descritas as tipologias dos ANTROPOSSOLOS encontrados na área de estudo:

Bem distribuídos por todo o perímetro visitado, os ANTROPOSSOLOS DECAPÍTICOS Parciálicos (9,9\%) (Figura 7), correspondem às áreas onde houve a retirada de horizontes superficiais, sem a exposição do horizonte $C$, e em alguns casos sujeitos a influência do lençol freático (Parciálicos Áquicos - 0,2\%), A motivação para a existência desses solos se dá pela construção civil. Esse solo está exposto à ação abrasiva dos ventos e da água, aumentando a possibilidade de erosão. Obras como cortes e aterros, unidos à declividade do relevo aumentam a probabilidade do fenômeno.

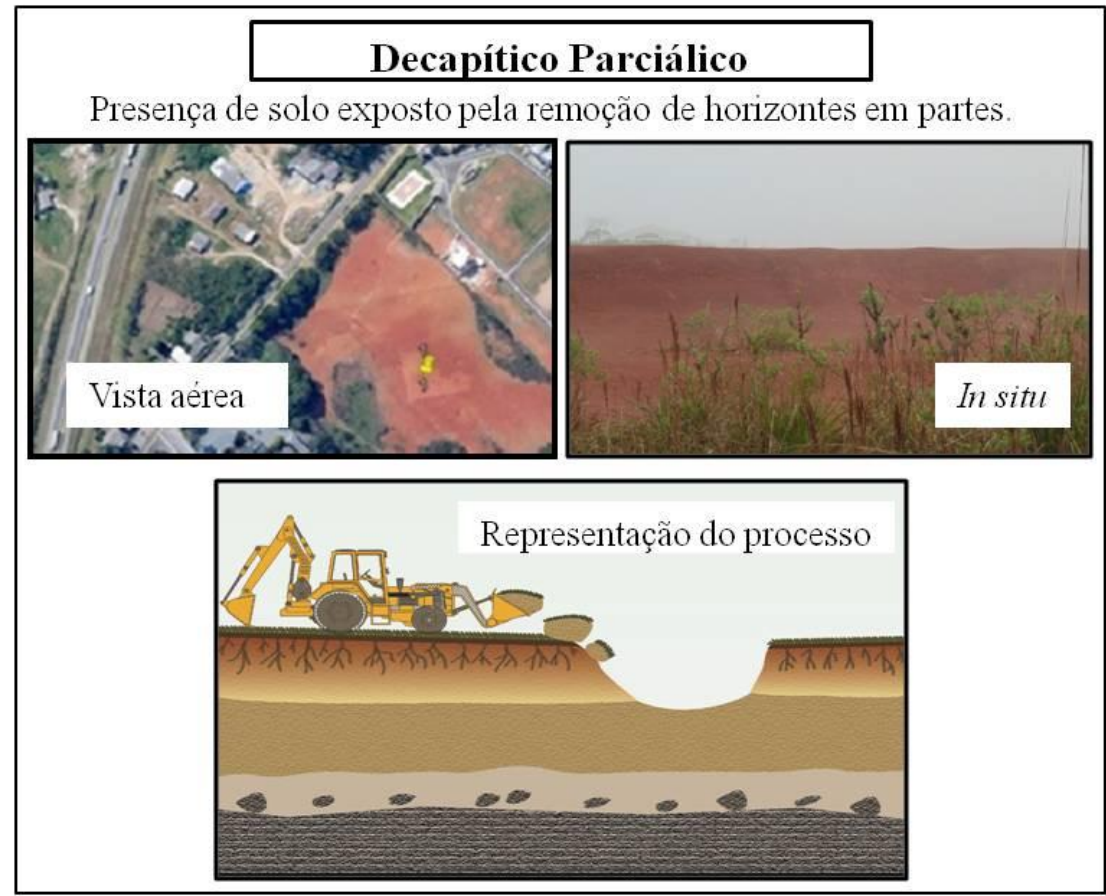

Figura 7 - Esquematização dos ANTROPOSSOLOS DECAPÍTICO Parciálico.

A subordem dos MOBílICOS (Figura 8) predomina na área de estudo com $55,3 \%$ ou 256,9 ha. São representativos em casos onde a mobilização de volumes parcial ou total acontece. Os ANTROPOSSOLOS MÉSCLICOS indicam a mistura dos horizontes dos solos. Sua existência está aliada a construções em áreas topograficamente inclinadas onde acontece a retirada do solo das porções mais altas para a deposição em áreas mais baixas, e às vezes, esses volumes demonstraram se compactados a fim de garantir a estabilidade dos terrenos. 


\section{MAPEAMENTO DE ANTROPOSSOLOS: ESTUDO DE CASO NO BAIRRO SANTA FELICIDADE (CURITIBA/PARANÁ)}

Para o arruamento foi admitido o caráter de ANTROPOSSOLO MOBÍLICO Inéquico, devido à remoção parcial de um ou mais horizontes superficiais e posteriormente o acréscimo de saibro onde é feita a compactação para pavimentação. Contudo essa subordem não foi quantificada em razão do mapeamento não ter sido feito por quadras e sim pela delimitação dos solos remanescentes.

\section{Mobílico Mésclico}

Volumes com alto grau de desorganização. Mobilização de horizontes e/ou materiais exóticos aos solos. Corte e aterro.

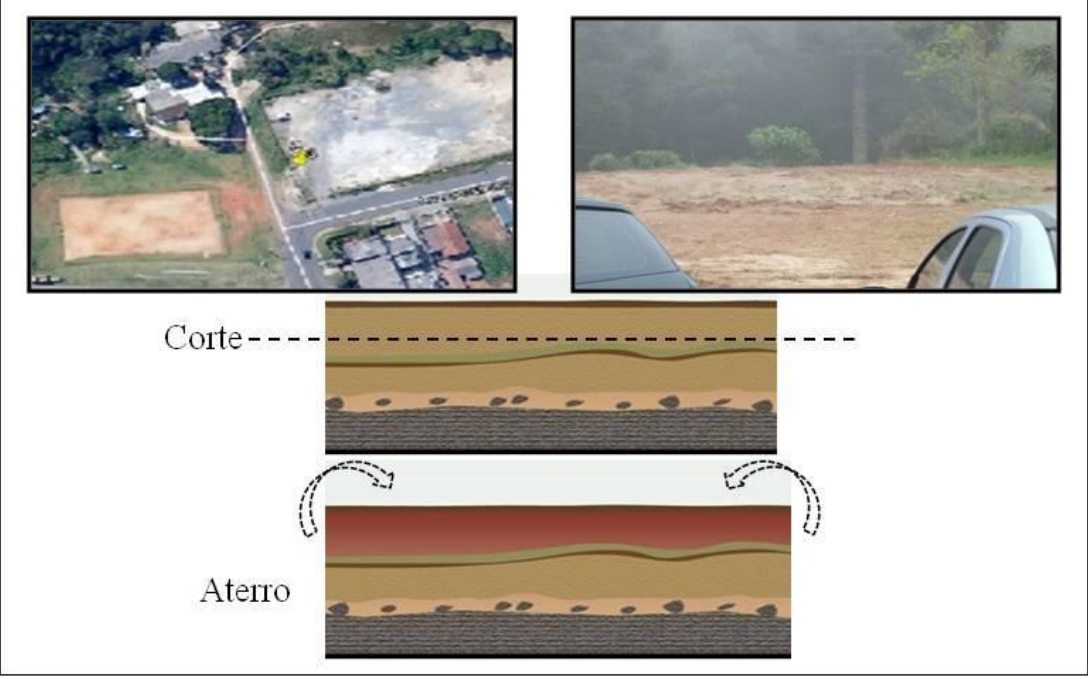

Figura 8 - Esquematização ANTROPOSSOLOS MOBÍLICO Mésclico.

Os ANTROPOSSOLOS SÔMICOS (Figura 9) aparecem com 0,7\% para os de caráter Mésclico e $6,0 \%$ para os ANTROPOSSOLOS SÔMICOS Mésclicos Áquicos. São solos mobilizados ou transportados de outras áreas. Foi encontrado um depósito de materiais que foram recortados das vias da cidade, esse lugar é da Prefeitura e abriga saibros e caliça. 


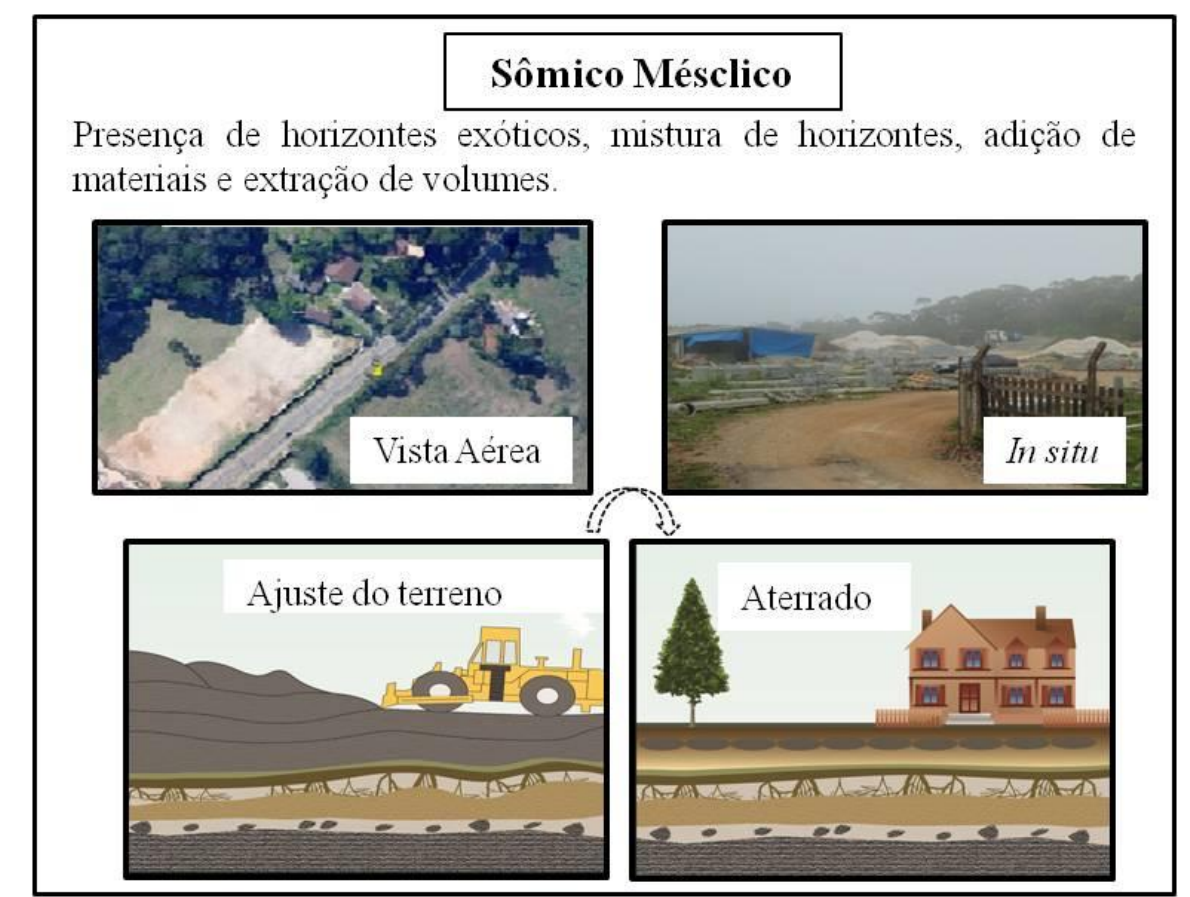

Figura 9 - Esquematização ANTROPOSSOLO SÔMICO Mésclico.

Devido a escala de 1:20.000 escolhida

para o mapeamento da região, algumas condições foram eliminadas na varredura, como a tipologia dos Líxicos Órtico (Figura 10) considerada como uma "área de ocorrência".
Contudo, esses foram identificados em terrenos abandonados, o que confirma a hipótese da EMBRAPA (2004) que indica o caráter Órtico como a condição habitualmente encontrada para a maioria dos LíxICOS.

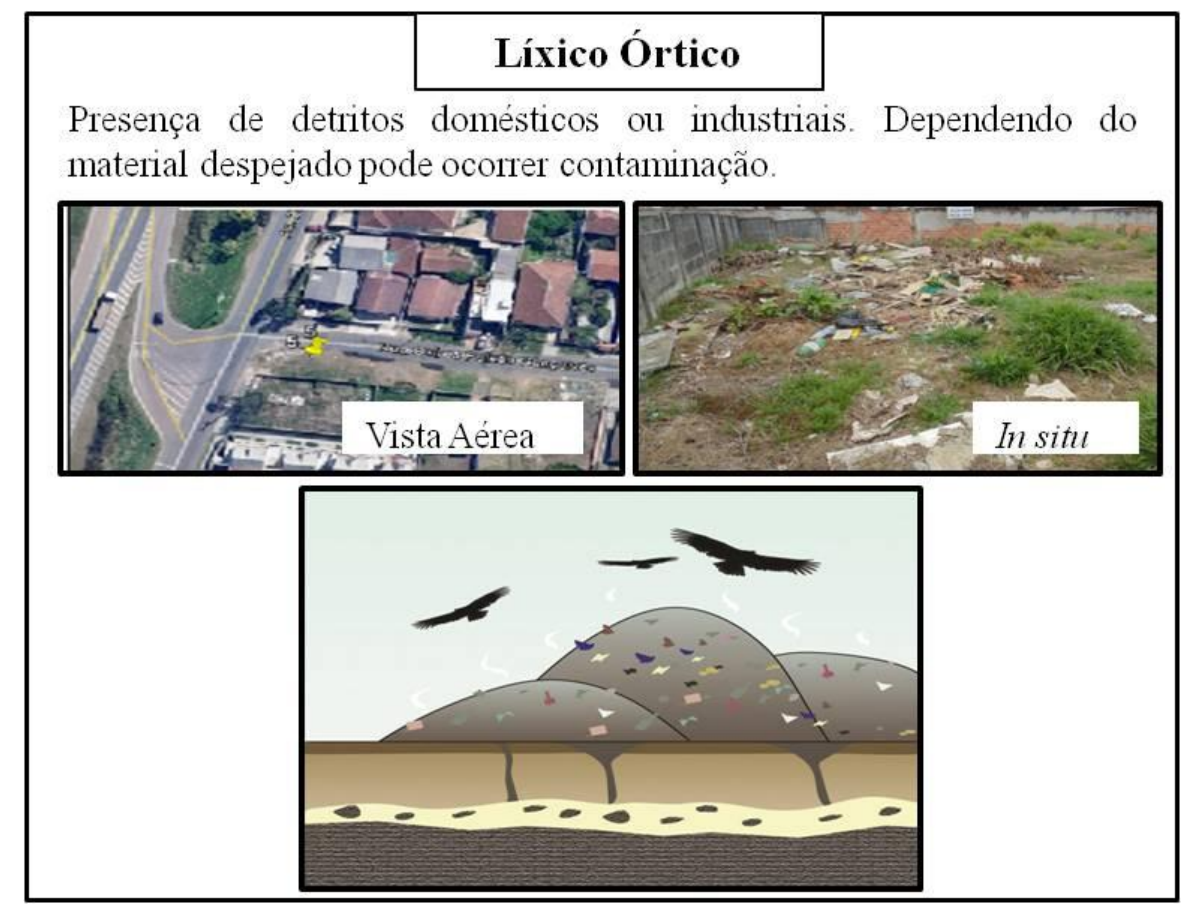

Figura 10 - Esquematização ANTROPOSSOLOS LíXICOS Órticos. 


\section{MAPEAMENTO DE ANTROPOSSOLOS: ESTUDO DE CASO NO BAIRRO SANTA FELICIDADE (CURITIBA/PARANÁ)}

Ressalta-se que as proposições para a identificação de cada volume são distintas, ou seja, cada classe carece de um método diferente para ser contemplada em sua plenitude. Para a classe dos ANTROPOSSOLOS DECAPÍTICOS considera-se adequada uma escala de até 1:3.000; já para as demais como os ANTROPOSSOLOS SÔMICOS, ANTROPOSSOLOS MOBÍLICOS e ANTROPOSSOLOS LÍXICOS estimase uma escala ultradetalhada como a 1:500. (CURCIO, 2016 ${ }^{15}$ ). Dessa maneira, sabe-se que os ANTROPOSSOLOS não são precisos e carecem estudos detalhados para o entendimento e mapeamento.

\section{CONSIDERAÇÕES FINAIS}

A busca de referências permitiu o entendimento do panorama em que a pesquisa em solos antropizados no Brasil e no mundo está. A carência de novas classificações para o enquadramento taxonômico desses volumes foi percebida devido a tal estudo. A construção intelectual é elementar a fim de obter resultados plausíveis não só para esse estudo, mas para qualquer ciência.

O conhecimento da dinâmica espaçotemporal da área de estudo permitiu o entendimento da paisagem que se faz de maneira ampla, onde o resultado de integração dos elementos de suporte e cobertura (físicos, biológicos e antrópicos), expressa em partes delimitáveis infinitamente, mas individualizadas por meio das relações entre elas, que organizam um complexo (sistema) conjunto em perpétua evolução (MONTEIRO, 2000, p. 39).

Através da atualização do uso da terra concluiu-se que ocorreram diversas modificações nos últimos 14 anos, entre elas a mais relevante pode-se citar, a intensa impermeabilização do solo e a consequente retirada da cobertura vegetal. 0 mapeamento dos solos remanescentes, através de parâmetros

15 CURCIO, G. R. Implicações funcionais dos ANTROPOSSOLOS. Colombo, 5 jan. 2017. Informação verbal. morfométricos, atualizou as informações para a região visto que as informações pedológicas oficiais não possuem o detalhe alcançado no presente trabalho, em escala 1:20.000.

O trabalho de campo foi imprescindível para a confirmação da hipótese da existência de ANTROPOSSOLOS no local. Na validação, feita pelo percurso da área de estudo, inconsistências foram encontradas devido à desatualização de algumas imagens de 2013. Contudo, esta situação permitiu conhecer a dinâmica de alguns locais do bairro, como a prática da agricultura e pecuária.

A história do local foi fundamental para o conhecimento dos tipos de usos da terra, tradicionalmente direcionados a agricultura, atualmente tomada pela construção civil. De fato, as atividades humanas foram esclarecidas e o panorama futuro pode ser previsto através dos produtos gerados como a atualização do Mapa de Uso e Cobertura da Terra e o Mapa de ANTROPOSSOLOS, produto final desse estudo.

Como considerações obtidas a partir dos perfis estudados vale frisar que após o início do processo metodológico foi possível compreender que a sua identificação, caracterização e mapeamento eram objetivos impossíveis de serem alcançados se fossem permeados pela ideia de representar a realidade.

Dessa forma, o mapeamento de Antropossolos apresentado nesse trabalho não é preciso em sua escala (é necessária uma escala de bastante detalhe) e consequentemente não o é em sua adequação às classes.

A produção do mapa de Antropossolos para a parte norte do bairro de Santa Felicidade possibilitou a abertura de novas perspectivas de estudo para a região que pode ser considerada como um expoente de qualidade ambiental em Curitiba, devido a sua arborização e arquitetura voltada a áreas verdes.

Pelo método de classificação dos ANTROPOSSOLOS até o $3^{\circ}$ nível categórico foi possível quantificar a antropização na área de estudo. Por fim, a aplicação da proposta da Ordem dos ANTROPOSSOLOS foi satisfatória e 


\section{MAPEAMENTO DE ANTROPOSSOLOS: ESTUDO DE CASO NO BAIRRO SANTA FELICIDADE \\ (CURITIBA/PARANÁ)}

novos estudos devem ser desenvolvidos a fim de reconhecer os limites e potencialidades da proposta, levando a discussão aos órgãos oficiais a fim de incluir as subordens em seus sistemas classificatórios.

\section{REFERÊNCIAS}

AB' SABER, A. N. Um conceito de Geomorfologia a serviço das pesquisas sobre o Quaternário. São Paulo: Instituto de Geografia, 1969.

BELÉM, A. L. G. Unidades de Paisagem no Bairro de Santa Felicidade (Curitiba-PR), Propostas ao Planejamento e Ordenamento da Paisagem, 2013. Dissertação de Mestrado. Departamento de Geografia, Universidade Federal do Paraná, Curitiba.

BERTRAND, G. Paisagem e Geografia Física Global - Esboço metodológico. Série Cadernos de Ciência da Terra, São Paulo, v.13, p. 1-27, 1972.

CRAUL, P. J. Urban Soils. College of Environmental Science \& Forestry

Syracuse, Nova York, 1992.

CURCIO, G.R; LIMA, V.C e GIAROLA, N.F.B. Serviço Nacional de Levantamento e Conservação de Solos. Antropossolos: Proposta de Ordem (1a Aproximação). Colombo: EMBRAPA Florestas, 2004. Disponível em: < https://www.infoteca.cnptia.embrapa.br/bitstrea $\mathrm{m} /$ doc/311308/1/doc101.pdf $>$. Acesso em: 1 mar, 2014

CURCIO, G. R.; UHLMANN, A.; SAVEGNANI, L. A geopedologia e a coleta de sementes de espécies arbóreas em florestas fluviais In: MEDEIROS, A. C. S.; VIBRANS, A. C. Coleta, manejo e armazenamento de sementes de espécies arbóreas da Mata Atlântica. Blumenau: Universidade Regional de Blumenau, p. 5-28, 2006.

DE KIMPE; MOREL, J. L. Urban Soil Management: A Growing Concern. In: Soil Science, v. 165, p. 31-44, 2000.
DEUPOUX. M. 1974. Ecossistema e paisagem. In: Métodos em Questão. IGEOG-USP- no 7, Sao Paulo.

DIAS, M. A. Mapeamento de Antropossolos na Porção Norte do Bairro de Santa Felicidade Curitiba/PR. Monografia de conclusão do curso de Geografia (Departamento de Geografia da UFPR), 2014.

FAO, Food and Agriculture Organization of the United Nations. World Reference Base for soil Resources. International soil classification system for naming soils and creating legends for soil maps. World Soil Resources Reports, p. 128, 2006.

World Reference Base for Soil Resources. International soil classification system for naming soils and creating legends for soil maps. World Soil Resources Reports No. 106. FAO, Rome, 2014.

GIASSON, E. Apostila Gênese e Classificação dos Solos para Graduação. Capítulo 1. Rio Grande do Sul, 2010.

IBGE, Instituto Brasileiro de Geografia e Estatística. Censo 2000. 2000. Disponível em <http://goo.gl/IscfYg>. Acesso em: 1 mai, 2014.

- Manual Técnico de Pedologia. 2. Edição. Rio de Janeiro, 2007. Disponível em < www.agrolink.com.br/.../manual\%20técnico\%20 de\%20pedologia.pdf>. Acesso em: 1 mai, 2014.

LEPSCH, I. F. Formação e conservação dos Solos. São Paulo: Oficina de Textos, 1993.

MACHADO, C. A. A Pesquisa de Depósitos Tecnogênicos no Brasil e no Mundo. Revista Tocantinense de Geografia, Araguaína (TO), Ano 01, no 02, p. 15-35, jan - jun, 2013.

MONTEIRO, C. A. de F. Geossistemas: A história de uma procura. São Paulo: Contexto, p. 127, 2000.

OJIMA, R; HOGAN, D. J. População, urbanização e ambiente no cenário das mudanças ambientais globais: debates e desafios para a demografia 


\section{MAPEAMENTO DE ANTROPOSSOLOS: ESTUDO DE CASO NO BAIRRO SANTA FELICIDADE \\ (CURITIBA/PARANÁ)}

brasileira. In: Anais do XVI ENCONTRO NACIONAL DE ESTUDOS POPULACIONAIS, Caxambu, 2008.

PEDRON, F. A; DALMOLIN, R. S. D; AZEVEDO, A. C de; KAMINSKI, J. Solos urbanos. Ciência Rural, Santa Maria, v. 34, n. 6, p. 1647-1653, 2004.

PEDRON, F. A; DALMOLIN, R. S. D; AZEVEDO, A. C de; BOtELHO, M. R; MENEZES, F. P. Levantamento e classificação de solos em áreas urbanas: importância, limitações e aplicações. In: Revista Brasileira de Agrociência, Pelotas, v. 13, n.2, p. 147-151, 2007.

PELOGGIA, A. U. G. A ação do homem enquanto ponto fundamental da Geologia do Tecnógeno: proposição teórica e discussão acerca do caso do município de São Paulo. Revista Brasileira de Geociências, v.27, p.257-268, 1997.

PELOGGIA, A.U.G. O homem e o ambiente geológico: geologia, sociedade e ocupação urbana no município de São Paulo. São Paulo: Xamã, 1998.

PELOGGIA, A. U. G. A Cidade, as Vertentes e as Várzeas: a transformação do Relevo pela Ação do Homem no Município de São Paulo. Revista do Departamento de Geografia, 16. p. 24-31, 2005.

POUYAT, R.V; SZLAVECZ K; YESILONIS, I. D; GROFFMAN P. M; SCHWARZ, K. Chemical, Physical, and Biological Characteristics of Urban Soils. SDA, Forest Service, p. 12-13, 2010.
SCHLEUB, U.; WU, Q.; BLUME, H. Variability of soils in urban and periurban

SCHMIDT, E. Avaliação Da Qualidade Ambiental Urbana Do Bairro De Santa Felicidade, Curitiba/Pr. Dissertação de Mestrado. Universidade Federal do Paraná. Setor de Ciências da Terra. Programa de Pós-Graduaçao em Geografia, 2009.

SCHUELER, T. The compaction of urban soils. Technical note $\mathrm{n}^{\circ}$ 107. Watershed Protection Techniques, v.3, n2, p.661-665, 2000. Disponível em http://goo.gl/JScQyK. Acesso em: Abr. de 2014.

SECCHI, C. E. Qualidade ambiental urbana em Presidente Prudente/Sp. Dissertação apresentada ao Programa de Pós Graduação em Geografia. Faculdade de Ciências e Tecnologia/UNESP. 2007.

SILVA, A. S. Solos Urbanos. Geomorfologia Urbana, cap. 2, p. 44-66, 2011.

STROGANOVA, M. N.; AGARKOVA, M. G. Urban Soils: experimental study and classification (exemplified by the soils of southwestern Moscow) Eurosian Soil Science, n.25, v. 3, p. 5969, 1993.

VALASKI, S.; NUCCI, J. C. Cobertura vegetal arbórea em condomínios residenciais horizontais do bairro Santa Felicidade - Curitiba/Pr. In: Geografia Ensino \& Pesquisa, v. 16, n.1, jan./jun. 2012. 